\title{
Panorama dos estudos sobre a linguagem da aviação
}

\section{Overview of studies about language and aviation}

Ana Eliza Pereira Bocorny*1

Pontifícia Universidade Católica do Rio Grande do Sul

Escola Superior de Propaganda e Marketing

Porto Alegre - Rio Grande do Sul / Brasil

RESUMO: A carência de estudos descritivos sobre a linguagem especializada da aviação dificulta a criação e o desenvolvimento de cursos de Inglês para Fins Específicos (doravante ESP) para essa área de conhecimento. A pesquisa aqui apresentada busca suprir em parte tal carência, na medida em que faz uma revisão de trabalhos que já foram produzidos sobre língua e aviação. Assim, o objetivo deste artigo é, ao analisar o surgimento e a evolução de estudos relacionados à linguagem da aviação, identificar as principais temáticas enfocadas por pesquisadores e escritores desde o surgimento da "arte de voar" até hoje, relacionando-as às diferentes áreas da Linguística Aplicada. Para tanto, livros, artigos e documentos foram identificados, listados, relacionados aos principais fatos históricos do período e categorizados conforme seus focos de estudo. Por fim, foi organizado um quadro referencial com os principais focos de estudo identificados. PALAVRAS-CHAVE: Linguagem especializada, linguagem especializada da aviação, ensino da linguagem especializada da aviação.

ABSTRACT: The lack of descriptive studies on the specialized language of aviation hinders the creation and development of English for Specific Purposes (hereafter ESP) courses for this area. This research seeks to remedy this deficiency as it presents a review of studies that have been produced about language and aviation. Thus, the purpose of this article is, while examining the emergence and evolution of language studies related to aviation, identify the main issues focused by researchers and writers since the emergence of "the art of flying" to date relating

\footnotetext{
* ana.bocorny@pucrs.br

${ }^{1}$ Doutora em Letras - Estudos da Linguagem (Teorias do Texto e do Discurso) pela UFRGS. Professora adjunta das faculdades de Letras e Ciências Aeronáuticas da PUCRS (ana.bocorny@pucrs.br) e do Curso de Relações Internacionais da Escola Superior de Propaganda e Marketing (abocorny@espm.br).
} 
them to different areas of Applied Linguistics. For this purpose books, articles and documents were identified, listed, related to major historical events of the period and categorized according to their focus of study. Finally, a frame of reference with the main focuses of the study identified was organized and presented.

KEYWORDS: Specialized language, specialized language of aviation, teaching the specialized language of aviation.

\section{Introdução}

The development of an academic discipline can be traced in the pages of the journals in which its teachers and researchers publish

(HEWINGS, 2002, p. 1).

O objetivo deste artigo é analisar o surgimento e a evolução de estudos relacionados à linguagem da aviação por meio das diferentes publicações da área. Ao fazer a revisão da literatura, buscamos identificar as principais temáticas enfocadas por pesquisadores e escritores desde o surgimento da "arte de voar" até hoje. Para tanto, livros, artigos e documentos foram listados e relacionados aos principais fatos históricos do período. Algumas dessas publicaçóes se destacam por sua importância e, por isso, são comentadas. Por fim, as temáticas motivadoras das obras foram apresentadas e organizadas em um quadro referencial.

\section{O francês como língua² da aviação - 1860 a 1918}

A relação entre língua e aviação começa com as primeiras tentativas de voar do homem e evolui ao longo de guerras e viagens ao espaço. Nem sempre o inglês, hoje língua franca da aviação, teve seu lugar assegurado como tal. A efervescência intelectual que caracteriza as principais potências mundiais do fim do século 18 e início do século 19 parece ser o pano de fundo ideal para o surgimento das primeiras obras sobre a aviação e, consequentemente, dos primeiros termos cunhados para referir a esse novo fenômeno, então designado como navigation aérienne ou navegação aérea.

\footnotetext{
${ }^{2}$ Entendemos que uma linguagem, ainda que parte da língua natural, represente o conhecimento especializado com base em certas restriçôes lexicais, semânticas e sintáticas. Não acreditamos que, nessa fase da história da aviação, houvesse consciência a respeito dessas restriçõos. Por essa razão, mantemos a denominação original de língua.
} 
No ano de 1855, em Paris, Arthur Mangin escreve La navigation aérienne - théoriquement et pratiquement demontreé - la direction de aerostats, obra pioneira sobre a teoria do voo, preocupada em descrever os aeroestatos. Muitas outras obras como essa são publicadas, a maior parte delas escrita em francês, mas também há títulos em alemão e inglês, demonstrando a existência de três grandes forças da aviação na época. Por volta de 1860, alguns termos ligados à atividade de voar já são utilizados em francês. Hélicoptère é cunhado em 1861, enquanto avion surge apenas em 1891 (GUILBERT, 1965, p. 9).

Com as obras que se ocupam em descrever as máquinas voadoras e a melhor técnica para tirá-las do chão, surgem glossários, dicionários e enciclopédias, como a Petite encyclopédie aéronautique (VENTOUDUCLAUX, 1910), o Dictionnaire illustré de la navigation aérienne (BAEDER, 1910), o Annuaire international de l'aéronautique: encyclopédie générale des locomotions aériennes (SENCIER et al., 1910), que cumprem a função de listar e definir o vocabulário especializado da área. O primeiro dicionário em inglês sobre a linguagem da aviação de que se tem notícia é o Dictionary of aviation, escrito por Pierce, em 1911.

Durante o período inicial da história da linguagem da aviação, é indiscutível o papel da língua francesa como principal fonte de termos dessa nova área de especialidade. Tal hegemonia se dilui à medida que outros países, como a Alemanha, a Inglaterra e os Estados Unidos, assumem seu papel como grandes potências no cenário mundial.

Começa a Primeira Guerra Mundial e, pela primeira vez na história da humanidade, acontecem embates aéreos. Muitas das obras publicadas nesse período, como Lexique aéronautique en six langues: français, anglais, allemand, italien, espagnol, espéranto (D'ARMAN, 1914) e Handbook of English and French terms for the use of military aviators (CHINARD, 1917), tratam o léxico aeronáutico sob uma perspectiva plurilíngue, e enfatizam termos utilizados na aviação militar. Não há muitas obras em alemão e não é possível notar ainda a hegemonia do inglês como língua da aviação. Impulsionados pela guerra, aviōes começam a ser produzidos em maior escala por fábricas como a Fokker, fundada em 1912, na Alemanha, e pela Boeing, criada em 1916, nos Estados Unidos.

Em seus primórdios, portanto, a grande maioria das obras relacionadas à linguagem da aviação é escrita em francês e tem como preocupação principal registrar o léxico aeronáutico em formação, buscando equivalências principalmente nas línguas dos países considerados potências mundiais. Dois títulos fogem desse padrão: Terminologie aéronautique, escrita por Paul Renard, em 1908, e French terminologies in the making: studies in conscious contributions to 
the vocabulary, escrita em 1918 por Harvey J. Swann. Segundo Guilbert (1965, p. 7), o livro de Renard é a primeira publicação que busca descrever a linguagem da aviação como tal. O livro de Swann procura mostrar os processos de formação da terminologia de diversos âmbitos da ciência e da técnica, na língua francesa. Dos oito capítulos deste livro, um é inteiramente dedicado à terminologia aeronáutica, em especial aos termos derivados de aéro como machine aérostatique, globe aérostatique, aérostat (SWANN, 1918, p. 67). Algumas das reflexóes feitas por Swann, ainda que escritas em 1918, soam muito atuais. Ele vê as terminologias como escolhas conscientes de seus usuários. Segundo ele, quando algum novo objeto é inventado, um conjunto de novas palavras deve ser encontrado ou criado para esse propósito. É então que a língua cresce de uma forma facilmente observável (SWANN, 1918, p. xiv). Swann também fala sobre o estabelecimento das terminologias dentro de uma língua, e do papel do usuário em aceitar um neologismo ou não. Ele diz, citando uma referência perdida de Charles Sumner, que "nada pode forçar um novo termo em uma língua contra a inclinação da grande maioria daqueles que a falam” (SWANN, 1918, p. 231).

\section{As muitas línguas da aviação - 1919 a 1943}

Durante o período entre guerras, a intensificação da demanda de tráfego aéreo, bem como o excedente de aeronaves e pilotos qualificados, levam à criação de empresas aéreas comerciais em vários países. No Brasil, a alemã Condor Syndykat e a francesa Aeropostale são autorizadas, em 1927, a precariamente realizar cabotagem com o objetivo de atender aos usuários e de integrar o território nacional. No dia 7 de maio do mesmo ano, a VARIG é registrada como empresa de aviação e obtém concessão para operar em território nacional, sendo a primeira empresa aérea comercial do Brasil. Em outubro de 1929, é criada a Nyrba do Brasil, que no ano seguinte torna-se a Panair do Brasil, subsidiária da Pan American Airways.

A maior parte dos pilotos dessas aeronaves são ex-pilotos militares, o que torna desnecessária a formação de pilotos civis. Ainda assim, cumprindo o previsto na ata da assembleia geral da sua constituição definitiva, de 1927, a VARIG cria a VAE (Varig Aero Esporte) em 1937,, com a função principal

\footnotetext{
${ }^{3}$ Conforme as letras $a$ e $c$ do artigo $4^{\circ}$ do referido documento, "A sociedade tem por fim: $a$ - o desenvolvimento da viação aérea mercante e o da instrução e desporto, para o que organizará linhas regulares de transporte de passageiros" e " $c$ - a instrução de aviadores" (VARIG, 1927, p. 8).
} 
de formar pilotos aviadores, inicialmente por meio de cursos de aeromodelismo e de pilotagem de planadores e, posteriormente, com o uso de aviōes motorizados. Ela é um misto de escola e departamento esportivo, "com estatutos e direção próprios, em que os interessados se associavam, mesmo sem fazerem parte do quadro de funcionários da VARIG" (BORDINI, 1996, p. 120).

Nessa época, não há registro do ensino da língua inglesa para os pilotos formados na VAE. O forte vínculo da VARIG com a Alemanha, no entanto, faz da língua alemã um requisito muito importante para essa nova transportadora. Em um possível diálogo apresentado por Bordini (1996) entre Otto Meyer e o recémcontratado Ruben Berta, a importância da língua alemã é revelada:

- Temos muito trabalho aqui, pois a empresa está começando, e há muita coisa a organizar. Você tem boa letra, escreve à máquina, tem redação própria e fala alemão? Era um requisito dominar a língua alemã, pois todos os técnicos só falavam essa língua, e os contatos pessoais ou por carta com o Condor Syndikat, na Alemanha, eram feitos, evidentemente, na língua germânica (BORDINI, 1996, p. 81).

O início da aviação comercial em nosso país, portanto, reproduz a força de três grandes potências da primeira guerra: a Alemanha e a França, por meio da Condor Syndykat/Aeropostale e da própria VARIG, e os Estados Unidos, via Panair do Brasil. No resto do mundo, a situação não é muito diferente. No final dos anos 1920, estações de rádio começam a surgir por toda a Europa. Os controladores dão informaçōes aos pilotos em todas as línguas. Os "pilotos tinham que ser multilíngues e, quando sobrevoando quatro países, falar quatro idiomas [...]. Pilotos da KLM falavam francês, inglês e alemão além de sua própria língua. Os pilotos britânicos todos falavam francês" (DOMOGALA, 1987, p. 10).

Em relação às obras publicadas no entre guerras, entretanto, o equilíbrio entre potências começa a se desfazer. Já é possível notar o destaque do inglês como língua da aviação. De 39 dicionários, glossários, manuais, enciclopédias e demais obras sobre o tema, 10 são escritas em inglês, quatro em alemão, duas em italiano, duas em francês, uma em espanhol, uma em holandês e uma em japonês. Outras sete obras são bilíngues, estando o inglês sempre presente. Destas, quatro são inglês/francês, duas inglês/espanhol e uma inglês/japonês. Por fim, oito publicaçōes são multilíngues, envolvendo algumas das línguas citadas acima e todas elas tendo como língua comum o inglês.

Da mesma forma que no período anterior, encontramos aqui algumas obras preocupadas em analisar e descrever os processos de formação que dão 
origem aos novos termos da linguagem da aviação. O artigo Notes sur le vocabulaire de l'aviation, escrito em 1930 por Edouard Portier na revista Revue de philologie française, L'aviation et la langue, escrito em 1934 por Ferdinand Brunot, e Terminologia aeronautica, uma publicação do Registro italiano navale, de 1936, são alguns exemplos citados por Guilbert (1965, p. 8).

Nesse período, o vocabulário originado com radioamadores é modificado e aperfeiçoado para ser usado como forma de comunicação entre pilotos e bases em terra. Nos anos de 1920 e 1930, essas palavras e frases inconscientemente agrupadas e utilizadas com frequência durante os voos acabam evoluindo e formalizando-se em um tipo de fraseologia recorrente que, mais tarde, irá dar origem aos padrões hoje utilizados pelo $\mathrm{FAA}^{4}$ e pela $\mathrm{ICAO}^{5}$ na comunicação realizada entre pilotos e controladores de voo.

\section{Estabelecimento do inglês como língua franca da aviação - 1944 a 1977}

O excedente de aeronaves e pilotos deixado pelo fim da Segunda Guerra Mundial é ainda maior do que o da Primeira Guerra, originando o florescimento e a internacionalização da aviação comercial. Em 1940, as empresas aéreas americanas transportam em torno de dois milhões de passageiros por ano em 350 aeronaves; em 1950, estes totais crescem para algo em torno de 17 milhões em mais de 1.000 aeronaves (CRYSTAL, 1997, p. 98). Os argumentos a favor de uma língua franca para a aviação tornam-se cada vez mais óbvios, e parece óbvio, também, que a língua escolhida seja o inglês, uma vez que tanto os líderes aliados quanto os principais fabricantes de aeronaves e a maioria dos pilotos do pós-guerra falam tal idioma (CRYSTAL, 1997, p. 99). A escolha do inglês passa pela criação da ICAO, em 1944. Responsável por estabelecer regras e padróes necessários para a segurança, eficiência e regularidade do transporte aéreo em seus 190 estados-membros, esta agência recomenda, em 1951, o inglês como língua a ser utilizada entre pilotos e controladores que falam línguas diferentes. A ICAO passa a ser, desde a sua criação, a organização individual que mais publica obras elencando o vocabulário especializado da aviação civil, totalizando 20 títulos de 1952 até 2001 .

\footnotetext{
${ }^{4}$ FAA - Federal Aviation Administration.

${ }^{5}$ ICAO - International Civil Aviation Organization.
} 
No Brasil, a língua inglesa também assume uma nova posição no que diz respeito à formação de pilotos civis. Em 1945, é publicado o primeiro dicionário aerotécnico inglês-português, escrito por Carlos Nayfeld. Em 1947, é criado o Departamento de Ensino da VARIG, com a responsabilidade de preparar pessoal técnico, em especial pilotos, para a empresa. A implementação desse departamento, considerado prioritário em função da intensificação e da modernização dos voos, passa por uma série de dificuldades em seu período inicial. Dentre os principais empecilhos, está a ausência de literatura sobre "tudo que se precisava ensinar" (BORDINI, 1996, p. 169). Menciona-se a importância de um "tradutor inglês-português" (BORDINI, 1996, p. 169) para o novo setor, de forma que textos de manuais da Força Aérea Americana e do $\mathrm{CAA}^{6}$ possam ser traduzidos para o português.

Ainda assim, aos poucos, o inglês começa a se estabelecer no âmbito de treinamento de pilotos no Brasil. O foco ainda não é o ensino da língua, mas, sim, a tradução dos textos que serão utilizados pelos aviadores em sua formação, na maioria das vezes realizada pelos próprios pilotos. É provável que, em função dessa atividade "tradutória" de alguns pilotos, o Comandante Dutra, experiente piloto da VARIG, inicie a elaboração de um glossário aerotécnico ${ }^{7}$ que até hoje surpreende por sua qualidade. Um pouco mais adiante, uma biblioteca técnica e de cultura geral, composta principalmente de obras norte-americanas e inglesas, começa a ser montada na VARIG. Segundo Bordini (1996, p. 172), "esses livros eram emprestados a interessados que, assim, começavam a levar mais a sério o estudo da língua inglesa”.

Em 1952, a VAE transforma-se em EVAER (Escola Varig de Aeronáutica). A primeira turma dessa nova fase da escola gradua-se em 1953, com 19 alunos. Nos 40 anos seguintes, aproximadamente, a EVAER será responsável pela formação da quase totalidade dos pilotos da VARIG.

Também em 1953 é publicado, com o título de International language for aviation: instrument flight, o relatório de um projeto encomendado pela CAA americana e ICAO, que tem por objetivo final a estruturação de uma

\footnotetext{
${ }^{6}$ CAA, aqui, ou Civil Aeronautics Administration. CAA, hoje, é o acrônimo de Civil Aviation Authority.

${ }^{7}$ O glossário aerotécnico escrito pelo Comandante Dutra (1979), uma publicação interna da VARIG, era distribuído a todos os alunos da EVAER durante o curso de formação de pilotos. Hoje, essa obra é copiada indiscriminadamente e muitas vezes vendida, sem que seu autor receba direitos autorais.
} 
linguagem baseada na língua inglesa, com um vocabulário restrito de aproximadamente 800 palavras a serem empregadas nas comunicaçóes radiotelefônicas (GRIGGS; RULON, 1953, p. 4). Esse relatório é especialmente importante por duas razóes: em primeiro lugar, porque mostra os primeiros indícios de um movimento que ganhará força no fim dos anos 1960 e início dos anos 1970, no sentido de buscar a padronização da linguagem utilizada entre controladores de voo e pilotos; e, em segundo lugar, porque é uma das primeiras publicações que relaciona linguagem da aviação a algo além de uma nomenclatura, ou seja, em sua nova acepção, linguagem da aviação passa a ser um código baseado na língua inglesa, que apresenta um vocabulário restrito, e que será utilizado nas comunicações radiotelefônicas entre pilotos e controladores de voo.

Em 1955, a VARIG obtém a licença para operar seu primeiro voo regular para os Estados Unidos: a linha Rio - Nova York - Rio. Apesar da internacionalização da empresa já ter-se iniciado em 1942, com a rota de Montevidéu, é com a linha de Nova York que surge a necessidade do ensino generalizado da língua inglesa. Nesse novo cenário, além de saber ler e entender publicaçôes técnicas em inglês, os pilotos brasileiros têm que ser capazes de se comunicar, via rádio, com os órgãos de controle de tráfego aéreo em uma das áreas mais congestionadas do mundo. A partir desse momento, os pilotos da VARIG têm que "manter diálogos complicados e tensos com órgãos de controle de tráfego, numa língua de certa forma desconhecida para a maioria dos brasileiros" (BORDINI, 1996, p. 229).

É intensificado, dentro da EVAER, o ensino da língua inglesa para pilotos. A ênfase é dada para a fraseologia utilizada pelos órgáos de controle de tráfego aéreo, com a contratação de dois instrutores especializados. Eles são treinados no Centro de Controle de Tráfego Aéreo da área de Nova York. Terminado o estágio dos instrutores, os pilotos responsáveis pela operação da nova linha são enviados para os Estados Unidos para fazerem um estágio de algumas semanas na mesma região. Lá os procedimentos de saída e chegada por instrumentos são treinados, com ênfase nos diálogos em inglês entre pilotos e controladores (BORDINI, 1996, p. 230).

Assim, a partir do florescimento e da internacionalização da aviação comercial e da consequente necessidade de piloto e controlador de voo utilizarem uma linguagem comum para comunicarem-se, surgem dois novos focos, vinculando linguagem e aviação: a necessidade de conhecer as especificidades do código linguístico utilizado entre a cabine de comando da 
aeronave e a torre de controle e a importância de saber como ensinar essa linguagem de especialidade aos novos pilotos comerciais que terão que ocupar as cabines das aeronaves nessa nova fase da aviação mundial. Com relação ao primeiro foco, dentro da área da linguística computacional, Zellig Harris introduz o conceito de sublanguage, ${ }^{8}$ a partir do qual muitos estudos são realizados na tentativa de desenvolver tradutores automáticos e outros recursos computacionais. Para tanto, a descrição detalhada do que se considera uma sublanguage é essencial.

The language of aviation vem exatamente ao encontro da necessidade de um material que pudesse ser usado para ensinar a linguagem da aviação e que, ao mesmo tempo, mostrasse um pouco de tal linguagem em seu contexto comunicativo real. Escrito por W. S. Barry em 1962 e reeditado em 1969, o livro, conforme o prefácio escrito pelo autor, "procura atender às necessidades de empregados de empresas aéreas em todo o mundo" (BARRY, 1969). De forma muito consistente, o livro deixa de ver a linguagem da aviação como uma lista de termos isolados, apresentados em glossários e dicionários, para mostrá-la em várias situações comunicativas especializadas da aviação.

A grande maioria das obras publicadas nesse período, no entanto, continua sendo constituída por glossários e dicionários ou obras tratando da história da terminologia da aviação, como os dois livros de Svante Stubelius (1958, 1960), Airship, aeroplane e aircraft - studies in the history of terms for aircraft in English, e Ballon, flying-machine, helicopter-further studies in the history of terms for aircraft in English, e o livro escrito por Guilbert (1965), La formation du vocabulaire de l'aviation. Os livros de Stubelius (1958, 1960) fazem uma investigação da história de nomes utilizados em língua inglesa para designar veículos sustentados pelo ar, dando ênfase especial aos termos mencionados nos títulos dos livros. O período estudado por ele inicia por volta de 1600, quando as primeiras referências a aircraft são feitas em textos escritos em língua inglesa, e estende-se até 1958 e 1960. Já o livro de Guilbert,

${ }^{8}$ Optamos por manter a palavra sublanguage em inglês ao longo do trabalho em vez de usar a tradução sublinguagem. Para Grishman (2001, p. 1) sublanguage é "a forma especializada de uma língua natural que é usada dentro de um domínio ou assunto específico. Exemplos de sublanguages são as linguagens dos relatórios meteorológicos, dos manuais de manutenção, dos artigos científicos sobre farmacologia, relatórios radiológicos e anúncios imobiliários. Uma sublanguage é caracterizada por vocabulário especializado, relaçóes semânticas e, em muitos casos, por uma sintaxe especializada" (GRISHMAN, 2001, p. 1). 
resultante de sua tese de doutoramento, é um estudo detalhado sobre os processos de formação do vocabulário da aviação, na língua francesa, no período que vai de 1861 a 1891.

\section{Busca de uma linguagem padronizada como forma de garantir a segurança - 1977 a 1997}

O processo de desregulamentação do transporte aéreo nos Estados Unidos tem como marco a assinatura, no dia 24 de outubro de 1978, do Airline Deregulation Act. Esse decreto elimina restrições relativas a aspectos comerciais dentro da aviação, como determinação de preços, número de frequências e capacidade das aeronaves (LIMA, 2004, p. 50). A partir daí, acirrase a competição entre as empresas aéreas, o que leva à falência gigantes como Eastern, Pan Am e Midway Airline. Surge uma nova maneira de entender a aviação, com o advento das empresas low cost, low fare, ou baixo custo, baixa tarifa. O avião populariza-se cada vez mais como meio de transporte. Em 1994, são transportados no mundo mais de 1,2 bilhões de passageiros (CRYSTAL, 1997, p. 98) e, em 1998, mais de 1,5 bilhões (ICAO, ${ }^{9} 2004$ ).

Com essa expansão, surge uma preocupação crescente com questóes relacionadas à segurança. Em março de 1977, acontece em Tenerife, nas Ilhas Canárias, o acidente com maior número de mortos na história da aviação. Por problemas de comunicação entre pilotos e controladores de voo, dois Boeing 747 colidem, matando 583 pessoas. Entre as causas para os acidentes que começam a se multiplicar, estão justamente problemas de comunicação. Nesse sentido, afirma Crystal (1997): "Um estudo relativo à prevenção de acidentes realizado pela Boeing descobriu que, na década de 1982-1991, os problemas de comunicação entre pilotos e controladores contribuíram para pelo menos $11 \%$ dos acidentes fatais ao redor do mundo" (CRYSTAL, 1997, p. 101).

\footnotetext{
${ }^{9}$ Fonte: Presentation by the President of the Council of the International Civil Aviation Organization (ICAO), Mr. Roberto González, on the Annual Reports of the Council for 2004, 2005 and 2006 and the Supplementary Report for the First Six Months of 2007 During the $36^{\mathrm{TH}}$ Session of the Assembly (Montreal, 20 September 2007) e (ICAO, 2004).
} 


\section{O âmbito dos atos de fala}

Em 1988, o artigo Language and Communication-Related Problems of Aviation Safety, ${ }^{10}$ de Steven Cushing, é um dos primeiros a vincular linguagem à segurança de voo. A partir da análise de acidentes e quase acidentes (near misses) relacionados a problemas de comunicação, Cushing sugere a criação de uma interface inteligente de voz, que torne as conversas entre piloto e controlador mais seguras. Cushing aprofunda seus estudos e, em 1994, escreve Fatal words: communication clashes and aircraft crashes, obra dividida em três partes. Assim como no artigo de 1988, Cushing parte da análise da comunicação entre pilotos e controladores de voo em situaçóes críticas. Ele identifica os fatores que comprometem a comunicação, dividindo-os em dois grupos. Na primeira parte do livro, são relatados problemas relacionados à linguagem, como ambiguidade e homofonia e, na segunda parte, o que Cushing chama de problemas não baseados em linguagem, como questões relacionadas a equipamentos ou ao estado dos sujeitos, como fadiga, impaciência e não cooperação. $\mathrm{Na}$ terceira e última parte do livro, o autor propõe soluções para os problemas identificados. Em última instância, ele sugere uma interface visual resistente a erro para a comunicação aeronáutica e uma interface de voz inteligente para o mesmo fim (CUSHING, 1994, p. xi). É interessante notar que a análise relatada na obra de Cushing, pela primeira vez, deixa de ser simplesmente linguística para considerar, também, outros fatores que afetam a comunicação, como a situação de enunciação, o estado físico dos sujeitos e o próprio equipamento através do qual se estabelece a comunicação.

\section{O âmbito da linguística computacional}

Os esforços de padronização, em um primeiro momento focados apenas no âmbito das operações aeronáuticas, estendem-se também para fora da cabine de comando. No final dos anos 1970 , a $\mathrm{AEA}^{11}$ pede à $\mathrm{AECMA}^{12}$ para investigar a capacidade de leitura e entendimento da documentação de

\footnotetext{
${ }^{10}$ Artigo apresentado na Annual Meetings of the American Association for Applied Linguistics (San Francisco, CA, Dezembro 1987) e no International Congress of Psychology (Sydney, Austrália, Agosto 1988).

${ }^{11}$ AEA - Association of European Airlines.

${ }^{12}$ AECMA - Association Europeéne des Constructeurs de Materiel Aerospatial.
} 
manutenção da indústria de aviação civil. A AECMA pede ajuda à AIA,${ }^{13}$ dos Estados Unidos. Os grupos da AECMA e da AIA pesquisam os textos de procedimentos e os manuais de manutenção. Esse é um marco muito importante, um divisor de águas no que diz respeito aos estudos da linguagem da aviação. A partir desse "convênio" patrocinado pela AEA, surge a preocupação de se criar um padrão de redação para os manuais de manutenção de aeronaves. O resultado desse esforço é o AECMA Simplified English Guide, que tem sua primeira edição lançada em 1986. Esse guia, mais tarde rebatizado de Specification ASD Simplified Technical English, estabelece regras de redação e um vocabulário controlado para a elaboração de manuais de manutenção aeronáutica. Mais tarde, Nevin e Johnson (2002, p. 251) chamarão o AECMA Simplified English de "linguagem controlada", ou seja, uma linguagem especialmente criada em um padrão mais simples e menos ambíguo.

Em paralelo ao movimento que busca a padronização das regras de redação dos manuais de manutenção, têm início, na Universidade de Montreal, algumas tentativas de tradução automática desses manuais. Dentro do âmbito da linguística computacional, a partir do conceito de sublanguage, surge o projeto TAUM ${ }^{14}$-AVIATION, com o objetivo principal de "desenvolver um sistema capaz de traduzir (automaticamente) ${ }^{15}$ manuais de manutenção aeronáutica” (ISABELLE; BOURBEAU, 1985, p. 1). Em 1979, é apresentado um protótipo restrito à tradução de textos dos manuais de manutenção do sistema hidráulico. Em 1980, "uma avaliação externa conclui que não era possível antever uma produção rentável imediata usando-se o TAUM-AVIATION" (ISABELLE; BOURBEAU, 1985, p. 1). Em função disso, o projeto é descontinuado. Ainda assim, permanece uma detalhada descrição da linguagem dos manuais de manutenção aeronáutica realizada por John Lehrberger e apresentada no terceiro capítulo do livro Sublanguage: studies of language in restricted domains.

Um outro trabalho que também relaciona a área de linguística computacional com a linguagem da aviação é a tese de doutoramento de Timothy Finin (1980). Com o objetivo de investigar como computadores podem entender melhor compostos nominais, ele examina exemplos retirados

\footnotetext{
${ }^{13}$ AIA - Aerospace Industries Association.

${ }^{14}$ TAUM (Traduction Automatique Université de Montréal).

15 (Nossa inclusão).
} 
de textos da área da aviação e sugere um dispositivo que ajude na sua interpretação automática. A sua descrição, no entanto, restringe-se apenas a essas unidades, sem uma preocupação maior em descrever a linguagem especializada de uma forma mais ampla.

\section{O âmbito do ensino das linguagens de especialidade}

É justamente neste período que o estudo das línguas para fins específicos (LSP), ${ }^{16}$ recebe um grande impulso, como forma de estabelecer a transferência de informação e comunicação entre leigos e especialistas (SAGER et al., 1980, p. xiii).

No Brasil, no final dos anos 1970 e anos 1980, o ensino da língua inglesa para pilotos no âmbito da EVAER tem três focos principais: a comunicação entre pilotos e controladores de tráfego aéreo via rádio, genericamente chamado de fraseologia; a comunicação em situações do dia a dia de um piloto, com diálogos em restaurantes e em check-in de hotéis, denominado inglês geral; e a leitura e tradução de manuais técnicos de operações, ou inglês técnico. $\mathrm{O}$ ensino da fraseologia fica a cargo de controladores de voo experientes; o inglês geral e o inglês técnico ficam, inicialmente, a cargo de comandantes, e posteriormente sob a responsabilidade de professores de inglês. Havendo poucos livros e estudos que discutam a melhor forma de se trabalhar com alunos com necessidades tão específicas, professores de inglês criam e recriam materiais com a ajuda de instrutores das áreas de manutenção e de pilotos mais experientes, o que possibilita que aprendam um pouco mais sobre a área de especialidade sobre a qual ensinam.

Nos anos 1980, surgem algumas reedições de materiais que haviam sido publicados em 1966. O objetivo desses livros é familiarizar os alunos de áreas técnicas e profissionais, com a terminologia usada em áreas como agricultura, negócios, computação, medicina, turismo, engenharia, entre tantas outras. A aviação, uma das áreas escolhidas, é enfocada sob três perspectivas principais: manutenção, tráfego aéreo e aeronaves/aviação geral. A série, preparada pela English Language Services, publicada pela Collier-Macmillan e batizada em 1966 de Special English, é relançada em 1984, com algumas modificações, pela editora Macmillan, com o nome de Career English. Ambas apresentam

\footnotetext{
${ }^{16}$ Sager et al.(1980) utilizam a palavra special (especial) ao invés de specific (específico) em Language for special purposes e English special languages.
} 
três títulos sobre aviação: General Aviation, ${ }^{17}$ Radiotelephony e Aviation Mechanics (1966) e Aviation Maintennance, International Air Traffic Control e International Jet Aircraft (1986).

A criação da IALCO ${ }^{18}$ e da IAEA ${ }^{19}$ hoje chamada de ICAEA ${ }^{20}$ é um marco muito importante para a história da linguagem da aviação. Preocupadas fundamentalmente em "melhorar o serviço prestado e a segurança nas aeronaves a partir da melhora das habilidades comunicativas funcionalmente orientadas que são exigidas pelas pessoas que trabalham em empresas aéreas", a partir de 1981 e 1984, respectivamente, essas associações começam a organizar fóruns de discussão e de troca de ideias entre os profissionais que têm a função de preparar pilotos, comissários e mecânicos de manutenção dentro das empresas aéreas a comunicarem-se em seus contextos profissionais. Todos parecem enfrentar os mesmos problemas, um dos quais é a falta de materiais e pesquisas que orientem atividades pedagógicas. As temáticas abordadas nesses encontros vão desde Simplified English, passando por lexicografia e pela terminologia utilizada no inglês para a aviação e pela testagem do inglês para a aviação. ${ }^{21}$ Os encontros, entretanto, apesar de gerar uma série de artigos, invariavelmente reúnem professores, ao invés de pesquisadores. Por essa razão, as discussões acabam centradas muito mais em relatos de experiências realizadas nas empresas aéreas e centros de treinamento do que na apresentação de resultados de pesquisas ou de reflexóes teóricas mais aprofundadas.

No fim dos anos 1980 e início dos anos 1990, duas obras são especialmente importantes para o ensino de inglês para aviação: Airspeak: radiotelephony communication for pilots (ROBERTSON, 1987) e English for Aircraft (SHAWCROSS, 1992a, 1992b). Sua temática mostra muito claramente a dicotomia que há no tratamento do inglês para aviação. A primeira tem como foco os pilotos na sua atividade de operar a aeronave e realizar a comunicação radiotelefônica com os controladores de voo. A segunda é direcionada aos mecânicos de manutenção e procura ajudá-los no entendimento dos textos dos manuais e na redação de itens de

\footnotetext{
17 Aviação geral.

${ }^{18}$ IALCO - International Airline Language and Communication Organization.

${ }^{19}$ IAEA - International Aviation English Association.

${ }^{20}$ ICAEA - International Civil Aviation English Association.

${ }^{21}$ Disponível em: <http://www.icaea.pata.pl/>.
} 
discrepância. ${ }^{22}$ Mais tarde, Philip Shawcross cria um curso em formato de cd-rom, denominado docWise, e também um site, ${ }^{23}$ sempre com o foco principal na linguagem presente na documentação aeronáutica, especialmente nos manuais de manutenção.

\section{O âmbito da terminologia tradicional e da terminografia}

Como se observa, as obras terminográficas são uma constante ao longo dos quase 150 anos da história da aviação, com glossários e dicionários especializados periodicamente sendo publicados, ainda que a qualidade de muitos possa ser questionada.

No Brasil, Demóstene Marinoto (1995) escreve sua tese de doutoramento utilizando o modelo proposto por Wüster para elaborar um vocabulário especializado bilíngue (inglês/português) da linguagem da aviação em três âmbitos: manutenção, controle de tráfego aéreo e operações aéreas. A obra tem um grande valor, na medida em que é uma das únicas obras de cunho terminográfico na área de especialidade da aviação a ser publicada em língua portuguesa desde o glossário aerotécnico de Dutra (1979), reunindo, assim, um grande número de termos e unidades terminológicas criadas a partir dos recentes avanços tecnológicos da aviação.

\section{Novas formas de ver a linguagem da aviação - o início do século 21}

Durante os anos 1980 e 1990, a simplificação e padronização da linguagem utilizada entre pilotos e controladores de voo é vista por especialistas como a melhor forma de evitar acidentes. Percebe-se, no entanto, que, apesar dos esforços padronizadores, os acidentes continuam acontecendo. Por mais extensiva que seja a fraseologia, ${ }^{24}$ ela não dá conta de todas as situações que podem surgir dentro da cabine de comando, especialmente em momentos de urgência ou emergência. Por outro lado, ela ainda é ignorada por alguns pilotos

\footnotetext{
${ }^{22}$ Um item de discrepância é a descrição que o piloto faz em um livro de bordo de qualquer problema (mecânico, hidráulico, elétrico, etc.) que ele tenha observado durante a operação da aeronave ou durante a inspeção externa dessa mesma aeronave. ${ }^{23}$ Disponível em: <http://www.bwise2.co.uk/>.

${ }^{24}$ Fraseologia aeronáutica, também chamada genericamente de fraseologia, dentro do contexto da aviação, significa um conjunto de frases-padrão que devem ser usadas durante a comunicação radiotelefônica entre piloto e controlador de voo.
} 
e controladores. Assim, ao contrário do que alguns especialistas imaginam, para evitar acidentes não basta simplificar e padronizar a linguagem utilizada entre pilotos e controladores de voo: é preciso que, além de saber a fraseologiapadrão da aeronáutica, os pilotos mesmos sejam proficientes no que os especialistas chamam de plain language.

A partir da constatação de que falhas mecânicas são causas menos frequentes de acidentes do que fatores humanos, mais atenção passa a ser dada pela ICAO a questôes relacionadas à comunicação radiotelefônica (ICAO, 2004, p. vii). Em 1998, a Resolução A 32-16 propõe um nível mínimo de proficiência na língua inglesa para pilotos e controladores de voo. Em 2000, a ICAO cria o PRICE SG ${ }^{25}$ um grupo de especialistas da Argentina, Canadá, China, França, Rússia, Ucrânia, Reino Unido, Estados Unidos, além de representantes da EUROCONTROL, ${ }^{26}$ IATA, ${ }^{27}$ IFALPA, ${ }^{28}$ IFATCA. ${ }^{29} \mathrm{O}$ objetivo desse grupo é o de estabelecer novas exigências de proficiência da língua inglesa para pilotos e controladores de voo, bem como o de desenvolver uma testagem padrão que determine se as exigências da ICAO estão sendo alcançadas, realizando os treinamentos necessários para alcançar tais padrōes. Entre 2000 e 2001, o grupo encontra-se três vezes, e muitos artigos sobre o tema são escritos, passando a comunicação entre piloto e controlador de voo a ser vista quase como sinônimo de linguagem da aviação em grande número de publicações.

O livro Beyond the black box (NEVILLE, 2004) é uma dessas obras. Ainda que restrinja o conceito de linguagem da aviação àquela realizada no contexto da cabine de comando (dos pilotos entre eles, e com outros sujeitos como controladores de voo), Neville (2004) amplia seu foco de observação, deixando de analisar apenas o aspecto verbal da interação para preocupar-se também com o uso que os pilotos fazem de uma gama de recursos disponíveis, à medida que realizam suas atividades de rotina. Um outro aspecto inovador no trabalho de Neville (2004) consiste em, ao contrário de Cushing (1994), descrever a talk in interaction dos pilotos em situações de rotina, em vez dos problemas de comunicação que resultam em acidentes e incidentes.

\footnotetext{
25 PRICE SG - Proficiency Requirements in Common English Study Group.

${ }^{26}$ Organização europeia para a segurança da navegação aérea.

${ }^{27}$ IATA - International Air Transport Association.

${ }^{28}$ IFALPA - International Federation of Air Line Pilots' Associations.

${ }^{29}$ IFATCA - International Federation of Air Traffic Controllers' Associations.
} 
Em 2004, a apresentação das novas exigências da ICAO é feita em Montreal para representantes das agências de aviação dos países-membros, de órgãos de classe de pilotos e controladores de voo e para pessoas envolvidas na formação desses profissionais. Fica estabelecida como data-limite para a implementação das novas exigências o mês de março de 2008. Um certo frenesi se estabelece no mercado editorial de ESP: não há materiais didáticos que preparem pilotos e controladores para as exigências de uma prova que ainda não foi criada. Da mesma forma, instaura-se um certo caos nas agências reguladoras de cada país: além das diretrizes estabelecidas pela ICAO, não há muitos modelos de testes no mundo que possam ser seguidos, nem profissionais, no âmbito das agências, que tenham experiência na formação linguística de pilotos e controladores de voo. A agência brasileira, em franca transição de Departamento de Aviação Civil para Agência Nacional de Aviação Civil, busca conhecer de que forma pilotos são formados, selecionados e capacitados na língua inglesa em nosso país. Para tanto, visitam instituições como a VARIG, a TAM e a Faculdade de Ciências Aeronáuticas da PUCRS. Observam, fazem gravações, buscam materiais. Por fim, em 2008, é lançado o Santos Dumont assessment test, prova de proficiência elaborada pela ANAC conforme as exigências da ICAO.

Toda essa movimentação causada pelas novas exigências da ICAO motiva a publicação de três livros-texto com o objetivo específico de preparar pilotos e/ou controladores de voo: Aviation English (EMERY; ROBERTS, 2008), Cleared for takeoff: English for pilots (MARINER, 2008) e English for aviation (ELLIS, 2008).

\section{Conclusão - Focos de estudo predominantes nas obras analisadas}

Conforme já referido, as linguagens de especialidade surgem em função do desenvolvimento técnico-científico. Comparativamente, a linguagem da aviação origina-se das primeiras intençóes relacionadas à habilidade do homem de voar e evolui recebendo múltiplos aportes a partir de diferentes áreas do conhecimento. Inicialmente, ela é genericamente entendida como o conjunto de termos ou expressões usadas nos vários âmbitos vinculados à atividade de voar, o que diferentes autores, dentre eles Sager (1993) e Temmermann (2000), chamam de terminologia (grafado com t minúsculo). Em um segundo momento, sob o olhar da Terminologia tradicional (no âmbito da terminografia), os termos são elencados em glossários e dicionários, com suas definições, e servem como referência para aqueles interessados na nova atividade, "com o propósito 
maior de padronizar o uso dos termos técnico-científicos, como forma de garantir a univocidade da comunicação entre especialistas" (KRIEGER, 2001, p. 24). A maior parte dos autores dessas obras são especialistas da área e não pessoas vinculadas aos estudos da linguagem. Esse olhar tradicional, vinculado à dimensão cognitiva da Terminologia, estende-se até os dias de hoje, concretizando-se na forma de glossários e dicionários especializados, que servem de referência à comunidade aeronáutica. Tais produtos terminográficos, mesmo os mais recentes, não revelam ainda contribuições advindas de uma visão comunicativa da Terminologia. Apresentam, por exemplo, os termos e suas definições, de forma descontextualizada. Um terceiro olhar da Terminologia sobre o objeto linguagem da aviação se consubstancia em uma perspectiva diacrônica, quando outro grupo de obras escritas por Renard (1908), Swann (1918), Stubelius (1958 e 1960) e Guilbert (1965), revelam preocupação em descrever a origem e os processos de formação dos termos.

Com o surgimento e a expansão da aviação comercial, a linguagem da área assume outra dimensão. A comunicação via rádio estabelece um novo contexto comunicativo especializado e, por conseguinte, a necessidade de um código linguístico $^{30}$ diferente daquele oferecido pela língua geral. Da mesma forma, a necessidade de consertar aeronaves e de operá-las ao redor do mundo obriga seus fabricantes a escrever manuais de manutenção e de operações, como forma de orientar o trabalho dos mecânicos e dos pilotos. Gradualmente, a aviação começa a ter seus termos integrados a um ambiente de comunicação especializado e, consequentemente, a um todo de significação que é o texto. Entretanto, obras escritas nesse período mantêm o cunho terminográfico e histórico do período anterior.

A internacionalização da aviação comercial, depois da Segunda Guerra Mundial, estabelece o inglês como língua franca da aviação. Surgem os conceitos de LSP e ESP. ${ }^{31}$ A linguagem da aviação restringe-se ao inglês

${ }^{30}$ Entendemos código linguístico, neste trabalho, conforme definição de Sager $e t$ al. (1980, p. 44). Segundo esse autor, uma mensagem consiste de text and intention (texto e intenção). Aquele que transmite a mensagem utiliza transmitting devices (recursos de transmissão) denominados por Sager et al. (1980) de code (código) e channel (canal). O code (código) poderá ser linguistic (linguístico) ou nonlinguistic (não linguístico). Um código não linguístico poderá ser, por exemplo, uma fórmula química; e o código linguístico, a explicação dessa fórmula. 
especializado da aviação, e se concretiza em três ambientes especializados diferentes: a terminologia (entendida como nomenclatura, rol de termos isolados), os textos especializados escritos dos manuais e os textos especializados orais da fraseologia aeronáutica. A linguagem padronizada passa a ser um sinônimo de segurança. Em função disso, muitas pesquisas são desenvolvidas tendo por foco principal evitar erros e acidentes por problemas de comunicação entre pilotos e controladores de voo. A literatura começa a tratar a linguagem especializada da aviação como sinônimo de comunicação radiotelefônica piloto/controlador, vista em todas as suas variáveis comunicativas. A linguística computacional/NLP, ${ }^{32}$ ao tratar das sublanguages, preocupa-se em descrever a linguagem dos manuais de manutenção, com o objetivo específico de desenvolver sistemas que possibilitem a tradução automática dos manuais de aviação e, por consequência, a tradução automática de outros gêneros textuais. O LSP/ESP, enquanto uma área de conhecimento, preocupa-se em estudar as formas de ensinar a linguagem de especialidade da aviação, fundamentalmente na situação comunicativa piloto/controlador de voo, buscando fazer generalizaçôes que contribuam para a melhora da prática em sala de aula.

O diagrama a seguir busca resumir, de forma esquemática, a relação entre as diferentes áreas de estudos da linguagem e as obras sobre linguagem da aviação. Mais recentemente, é possível notar que trabalhos como o de Bocorny (2008), Sarmento (2008) e Prado (2010) mostram uma nova possibilidade e muito provavelmente uma tendência, qual seja, a utilização da Linguística de Corpus para descrever e, consequentemente, conhecer melhor a linguagem especializada da aviação. Tais pesquisas têm como foco o ensino, e encontram-se na interface entre a Terminologia e os estudos das linguagens especializadas, mais especificamente na Terminologia aplicada ao ensino de linguagens especializadas, como entende Cabré (2005, p. 18). A vinculação com a linguística computacional acontece àmedida que os meios oferecidos pela Linguística de Corpus são utilizados para a descrição desta linguagem especializada.

${ }^{31}$ LSP é utilizado para designar Language for Specific/Special Purposes, usualmente traduzido para o português como "Língua para Fins Específicos". ESP é utilizado para designar English for Specific Purposes, usualmente traduzido para o português como "Inglês para Fins Específicos".

${ }^{32}$ NLP ou Natural Language Processing. 


\section{QUADRO 1}

Áreas de estudos da linguagem X obras sobre a linguagem da aviação

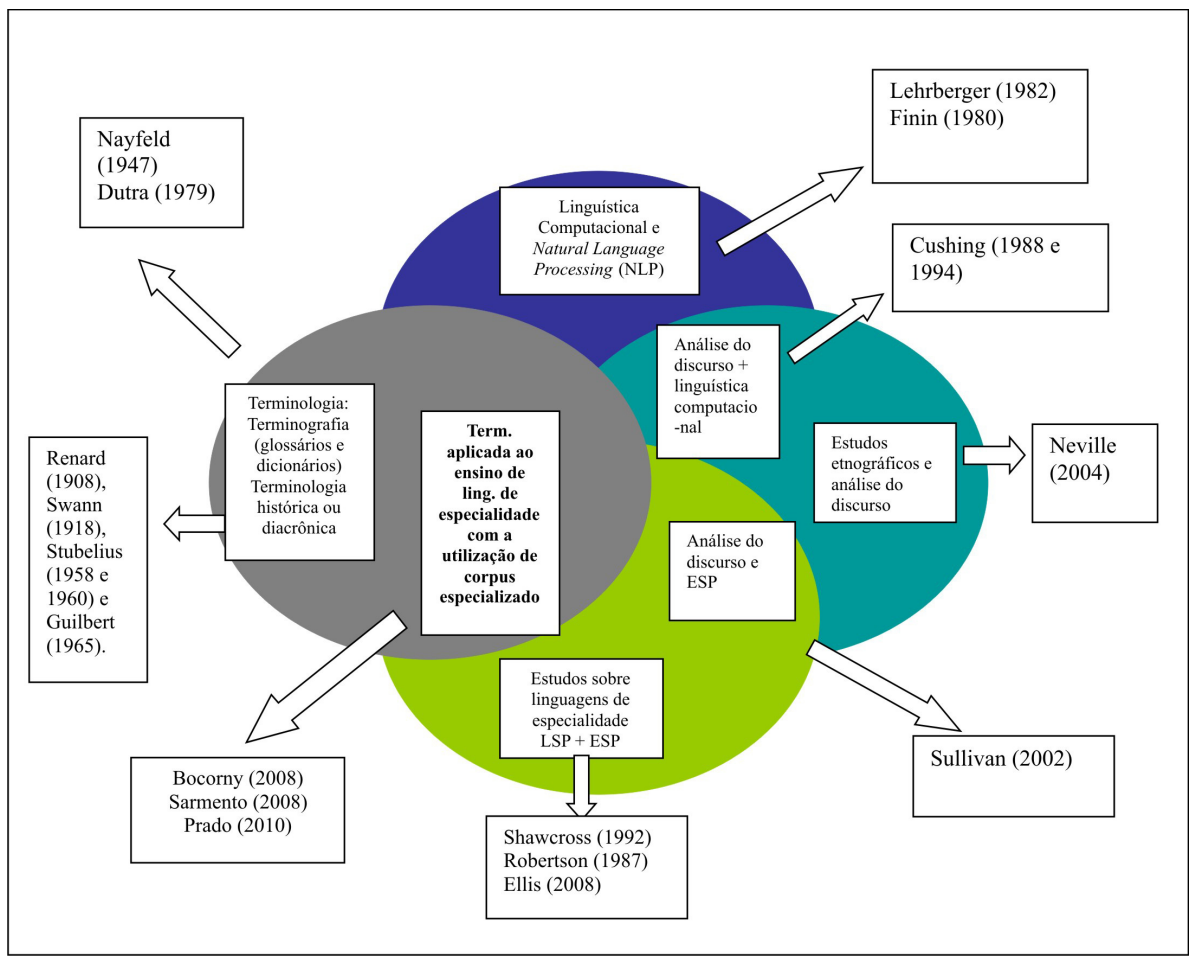

Como mencionado inicialmente, a presente pesquisa pretendia, com base na compilação e análise de trabalhos produzidos sobre língua e aviação, analisar o surgimento e a evolução de estudos relacionados a essa área, identificando suas principais temáticas. Esperamos que, nesse sentido, este trabalho tenha ajudado àqueles que busquem conhecer mais sobre linguagem e aviação.

\section{Referências bibliográficas}

ASD SIMPLIFIED TECHNICAL ENGLISH. Manuais de manutenção aeronáutica. Bruxelas. Disponível em: <http://www.asd-ste100.org/stemg.htm>. Acesso em: 4 mar. 2008.

BAEDER, F. Dictionnaire illustré de la navigation aérienne. Paris: Librairie Aéronautique, 1910. 
BARRY, W. S. The language of aviation. London: Chatto \& Windus in Association with the British Broadcasting Corp., 1969.

BOCORNY, A. E. P. Descrição das unidades especializadas poliléxicas nominais no âmbito da aviação: subsídios para o ensino de inglês para fins específicos (ESP). 2008. 230 f. Tese (Doutorado em Estudos Linguísticos - Teorias do Texto e do Discurso, Lexicografia e Terminologia: Relaçōes Textuais) - Faculdade de Letras, Universidade Federal do Rio Grande do Sul, Porto Alegre, 2008. Disponível em: $<$ http://www.lume.ufrgs.br/bitstream/handle/10183/15548/000678237.pdf? sequence $=1>$. Acesso em: 4 mar 2010 .

BORDINI, R. Céus desconhecidos. Porto Alegre: Magister, 1996.

BWISE2. Disponível em: <http://www.bwise2.co.uk/>. Acesso em: 5 mar. 2008.

CABRÉ, M. T. Recursos lingüisticos en la enseñanza de lenguas de especialidad. Barcelona: Universitat Pompeu Fabra, 2005. Disponível em: <http:// cvc.cervantes.es/obref/aeter/conferencias/cabre.htm>. Acesso em: 20 jul. 2008. CABRÉ, M. T.; VIDAL, V. Estrategias para la enseñanza de combinaciones léxicas metafóricas en un curso de lenguas para fines específicos. In: JUAN, M.; AMENGUAL, M.; SALAZAR, J. (Ed.). Lingüistica Aplicada en la Sociedad de la Información y la Comunicación. Palma de Mallorca: Universitat de les Illes Balears, 2006. p. 187-195. Disponível em: <http://www.upf.edu/pdi/dtf/ teresa.cabre/docums/ca06aela.pdf>. Acesso em: 25 mar. 2008.

CHINARD, G. Handbook of English and French terms for the use of military aviators. 2 ed. Berkeley: University of California Press, 1917.

CRYSTAL, D. English as a global language. Cambridge: Cambridge University Press, 1997.

CUSHING, S. Fatal words: communication clashes and aircraft crashes. Chicago: University of Chicago Press, 1994.

CUSHING, S. Language and communication-related problems of aviation safety. Proceedings of the 1987 Annual Meeting of the American Association for Applied Linguistics. San Francisco: AAL, 1988.

D'ARMAN, R. Lexique aéronautique en six langues: français, anglais, allemande italien, espagnol, espéranto. Paris: Librairie Aéronautique, 1914.

DOMOGALA, P. The bad old days. INTERNATIONAL AVIATION ENGLISH TEACHING FORUM, 3, Proceedings... Paris-Orly (France), 1987.

DUTRA, L. C. S. Glossário aerotécnico: inglês-português. 2. ed. São Paulo: Ministério de Aviação, 1979.

ELLIS, S. English for aviation. [s. 1.]: Oxford University Press, 2008. 
EMERY, H.; ROBERTS, A. Aviation English student's book with cd-rom. [s. 1.]: Macmillan Education, 2008.

FININ, T. The semantic interpretation of compound nominals. Champaign, IL, USA: University of Illinois at Urbana-Champaign, 1980.

GRIGGS, D. T.; RULON, P. J. International language for aviation: instrument flight. Cambridge: Educational Research Corp, 1953.

GRISHMAN, R. Adaptive information extraction and sublanguage analysis. Computer Science Department, New York: New York University, 2001.

GUILBERT, L. La formation du vocabulaire de l'aviation. Paris: Librairie Larousse, 1965.

HEWINGS, M. A History of ESP through 'English for Specific Purposes'. English for Specific Purposes World. Electronic Journal, v. 1, n. 3, p. 1-11, 2002. Disponível em: <www.esp-world.info/contents.htm>. Acesso em: 09 fev. 2007.

ICAO. Manual on the implementation of ICAO language proficiency requirements. DOC 9835. ICAO, 2004. Disponível em <http://caa.gateway.bg/upload/docs/ 9835_1_ed.pdf>. Acesso em: 30 mar. 2007.

INTERNATIONAL CIVIL AVIATION ENGLISH ASSOCIATION (ICAEA). Disponível em: <http://www.icaea.pata.pl/>. Acesso em: 30 mar. 2007.

ISABELLE, P.; BOURBEAU, L. Taum-aviation: its technical, features and some experimental results. Computational Linguistics, n. 11, p. 18-27, 1985.

KRIEGER, M. G. A face lingüística da terminologia. In: KRIEGER, M. G.; MACIEL, A. M. B. (Org.). Temas de Terminologia. Porto Alegre: Editora da UFRGS, 2001. p. 23-33.

LEHRBERGER, J. Automatic translation and the concept of sublanguage. In: KITTREDGE, R.; LEHRBERGER, J. (Ed.). Sublanguage: studies of language in restricted semantic domains. Berlin: Walter de Gruyter, 1982. p. 81-106.

LIMA, J. S. C. A. P. Empresa aérea de baixo custo e baixa tarifa no Brasil: contribuiçōes de um novo modelo de empresa aérea para o turismo doméstico. 2004. Dissertação (Mestrado em Turismo). Universidade de Caxias do Sul, Caxias do Sul, 2004.

MARINER, L. Cleared for takeoff: English for pilots - books 1 and 2 with cd-rom. Irvine (USA): AE Link Publications, Inc., 2008.

MARINOTO, D. Para a elaboração de um vocabulário especializado bilíngüe (inglês-português) da linguagem da aviação. 1995. Tese (Doutorado em Linguística) - Universidade de São Paulo, São Paulo, 1995.

NAYFELD, C. Dicionário aerotécnico inglês-português. Rio de Janeiro: Cia. Editora Leitura, 1945. 
NEVILLE, M. Beyond the black box: talk-in-interaction in the airline cockpit. London: Ashgate Publishing, 2004.

NEVIN, B. E.; JOHNSON, S. M. The legacy of Zellig Harris: Language and information into the 21st century (Amsterdam studies in the theory and history of linguistic science). Amsterdam: J. Benjamins Pub, 2002. v. 228-229.

PRADO, M. C. A. Corpus de Inglês Oral na Aviação em situações anormais. Aviation in Focus, Porto Alegre, v. 1, n. 1, p. 48-57 ago./dez. 2010. Disponível em: <http://revistaseletronicas.pucrs.br/ojs/index.php/aviation/article/view/ 8149/5836>. Acesso em: 25 fev. 2011.

RENARD, P. Terminologie aéronautique. Omnia: Revue pratique de locomotion, Paris, n. 120, p. 244-246, 18 abr. 1908.

ROBERTSON, F. A. Airspeak: radiotelephony communication for pilots. New York: Prentice-Hall, 1987.

SAGER, J. C. et al. English special languages: principles and practice in science and technology. Wiesbaden: Brandstetter, 1980.

. Curso práctico sobre el procesamiento de la terminología (Biblioteca del libro, 57). Madrid: Fundación Germán Sánchez Ruipérez, 1993.

SARMENTO, S. O uso dos verbos modais em manuais de aviação em inglês: um estudo baseado em corpus. 2008. 262 f. Tese (Doutorado em Estudos Linguísticos - Teorias do Texto e do Discurso, Lexicografia e Terminologia: Relaçôes Textuais) - Faculdade de Letras, Universidade Federal do Rio Grande do Sul, Porto Alegre, 2008. Disponível em: <http://www.lume.ufrgs.br/ bitstream/handle/10183/15568/000685529.pdf?sequence=1>. Acesso em: 04 mar. 2010.

SHAWCROSS, P. English for aircraft 1, documentation handbook. Paris: Belin, 1992a.

SHAWCROSS, P. English for aircraft 2, system maintenance. Paris: Belin, $1992 \mathrm{~b}$. SENCIER. P. Annuaire international de l'aéronautique: encyclopédie générale des locomotions aériennes. Paris: Coblet et Marchal, 1910.

STUBELIUS, S. Airship, aeroplane, aircraft: studies in the history of terms for aircraft in English. Göteborgs Universitet Departament of English, 1958.

STUBELIUS, S. Balloon, flying-machine, helicopter: further studies in the history of terms for aircraft in English. Gothenburg (Sweden): Göteborgs Universitet, 1960.

SULLIVAN, P.; GIRGINER, H. The use of discourse analysis to enhance ESP teacher knowledge: an example using aviation English. English for Specific Purposes, v. 21, n. 4, p. 397-404, 14 maio 2002. Disponível em: <http:// 
www.sciencedirect.com/science/article/pii/S0889490601000424>. Acesso em: 25 mar. 2008.

SWANN, H. J. French Terminologies in the Making: studies in conscious contributions to the vocabulary. New York: Columbia University Press, 1918. TEMMERMANN, R. Towards new ways of therminology description. The sociocognitive approach. Philadelphia: John Benjamins, 2000.

UNWALLA, M. AECMA simplified English. 2004. Disponível em: <http:// www.techscribe.co.uk/ta/aecma-simplified-English.pdf>. Acesso em: 20 nov. 2007.

VARIG. Ata da Assembléia Geral da Constituição Definitiva. Porto Alegre, 1927. VENTOU-DUCLAUX. Petite encyclopédie aéronautique. Paris: Paris, F. L. Vivien 1910.

YULE, G. The study of flanguage. Cambridge [U.A.]: Cambridge University Press, 1996.

ZELLIG, H. Mathematical structures of language. Interscience tracts in pure and applied mathematics. n. 21. New York: Interscience Publishers, 1968.

Recebido em 19/3/2011. Aprovado em 13/7/2011. 